MATHEMATICAL ASSOCIATION

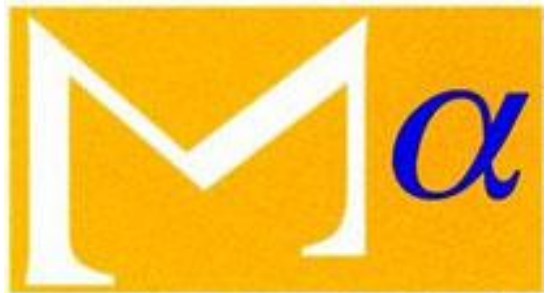

supporting mathematics in education

\title{
547. Intersections of Curves in Polars
}

Author(s): E. H. Smart

Source: The Mathematical Gazette, Vol. 10, No. 146 (May, 1920), p. 68

Published by: Mathematical Association

Stable URL: http://www.jstor.org/stable/3604783

Accessed: 17-11-2015 05:55 UTC

Your use of the JSTOR archive indicates your acceptance of the Terms \& Conditions of Use, available at http://www.jstor.org/page/ info/about/policies/terms.jsp

JSTOR is a not-for-profit service that helps scholars, researchers, and students discover, use, and build upon a wide range of content in a trusted digital archive. We use information technology and tools to increase productivity and facilitate new forms of scholarship. For more information about JSTOR, please contact support@jstor.org. 
The three cognate inequalities involving sines, cosines and tangents respectively, in virtue of the identity $\sin \theta=\tan \theta \cos \theta$, are logically related inasmuch as the cosine inequality can at once be deduced from the other two; but as they are harder to prove, this relation is not of much importance.

R. F. Muirilead.

546. [U.] When paying a visit to the Pearl Mosque in the Fort at Agra in December, 1915, I noticed the sundial standing in the S.E. corner of the courtyard. The dial face is as the figure. $O A$ is about $\frac{1}{3}$ of the radius,

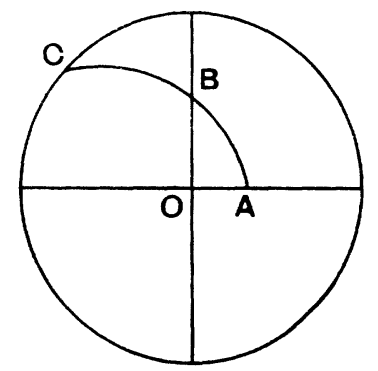

$O B$ is about $\frac{1}{2}$ of the radius, $A B C$ is an arc. The diameters are at right angles. The gnomon is not there. Can somebody inform me how this worked?

T. V. Philpott.

547. [ $\mathbf{L}^{1}$. 17.] Intersections of Curves in Polars.

An elementary point that is often overlooked is that the intersections of (say) $r=f(\theta)$ and $r=\psi(\theta)$ are not, in general, completely given by the equation

$$
f(\theta)=\psi(\theta) \text {. }
$$

For example, the conics $\frac{10}{r}=2+5 \cos \theta$ and $\frac{10}{r}=5-4 \cos \theta$ intersect actually in four real points, two only of which are got by equating the values of $r$.

The root of the matter, of course, lies in the fact that the representation of the position of a point by polar coordinates is not unique, $(r, \theta)$ and $(-r,(2 \kappa+1) \pi+\theta),(\kappa$ integral $)$, being identical.

In tracing polar curves, for some branches $r$ is positive and for others negative. (1) gives only the vectorial angles of points of intersection of branches for which $r$ has the same length. To get those of branches for which $r$ has opposite signs, write one of the equations (say $r=\psi(\theta)$ ) in its equivalent form,

$$
-r=\psi((2 \kappa+1) \pi+\theta) \text {. }
$$

In this form the positive and negative branches exchange rôles, and we can now equate radii vectores again and get for the remaining intersections

$$
f(\theta)+\psi((2 \kappa+1) \pi+\theta)=0 .
$$

(1) and (2) together give the complete intersections of the curves.

Of course it often happens that the solutions of (2) are included in (1), but this is not true in general.

E. H. Smart. 